\title{
El gran camino Inka: construyendo un Imperio. Una exhibición sobre el Qhapaq Ñan en el Museo Nacional del Indígena Americano, Smithsonian Institution
}

\author{
RAMIRO MATOS ${ }^{A}$
}

El comité organizador del "Taller Internacional Qhapaq Ñan I", realizado en Atacama, Chile, tuvo la gentileza de invitarme para hablar sobre la exhibición que el Museo Nacional del Indígena Americano, de la Smithsonian Institution, estuvo preparando en aquel entonces sobre el sistema vial inka. La exhibición, de carácter bilingüe, se tituló: "The great Inka Road. Engineering an empire" ("El Gran Camino Inka: construyendo un imperio") y fue inaugurada el 26 de junio de 2015 en el edificio principal del museo, ubicado en Washington, D.C. Con la muestra, Smithsonian se adhiere al homenaje que la sociedad contemporánea tributa a la monumental obra inka, declarada Patrimonio Cultural de la Humanidad por la UNESCO en su reunión anual realizada el 21 de junio de 2014 en Qatar. ${ }^{1}$ Las seis repúblicas de la region andina que tienen el privilegio de heredar este hermoso legado son: Colombia, Ecuador, Perú, Bolivia, Chile y Argentina.

La exhibición coincidió con el 1 1er aniversario de la declaración del Qhapaq Ñan como Patrimonio de la Humanidad. Las embajadas de los seis países acreditados ante la Organización de Estados Americanos (OEA) y los directivos de Smithsonian se unieron para honrar el legado inka. Como parte del programa inaugural, se organizó una mesa redonda en la OEA con ponentes de los países andinos y un simposio de dos días en el museo con participación de expertos en el tema. Tanto el embajador de la Misión Permanente del Perú ante la OEA, Dr. Juan Jiménez Mayor, como el subsecretario para Historia, Arte y Cultura del Smithsonian, Dr. Richard Kurin, destacaron el valor histórico, cultural, social y político del Qhapaq Ñan.

Los inkas organizaron un imperio original, inédito, andino, diferente a los conocidos en la historia universal, el más extenso y complejo del Nuevo Mundo. Lo llamaron Tawantinsuyu, "territorio de los cuatro suyu unidos". Para afirmar la expansión y dominio de los territorios conquistados, habilitaron una estratégica red vial dedicada a cohesionar y facilitar funciones administrativas del Estado. Aprovecharon los caminos pre-existentes, construyeron otros nuevos y organizaron el sistema vial de mayor longitud y eficacia en la América precolombina. Se estima que la longitud de esta red era de unos $40.000 \mathrm{~km}$. Fue la infraestructura más completa, rápida y eficiente para el transporte, comunicaciones e interacción en América durante el

\footnotetext{
A Ramiro Matos, curador para América Latina y curador de la Exposición, Smithsonian Institute, email: matosr@si.edu
} 
siglo XV. Por su monumentalidad y magnificencia, el Camino Inka fue ya comparado por los españoles en el siglo XVI con el romano, porque no existía un sistema similar en Europa más que los residuos del camino romano. El camino andino fue llamado Qhapaq Ñan, que en la lengua quechua y puquina quiere decir "Camino del Señor". Ñan es quechua y significa "camino", mientras qhapaq es lengua puquina y denota "señor". El estudio pionero de John Hyslop (1984), que incluye un mapa sobre el sistema vial inka, tantas veces reproducido en los ensayos dedicados al tema, ha sido un libro-guía. Para la exhibición, los colegas de los seis países que trabajaron bajo la coordinación de UNESCO, tuvieron la generosidad de compartir sus datos con nosotros, con los cuales preparamos un mapa reactualizado (fig. 1).

El territorio inka se extendía hasta donde llegaba el Qhapaq Ñan. Este fue un símbolo del Estado, habilitado para el control político; al mismo tiempo que un agente civilizador, responsable de la difusión de tecnologías, creencias, costumbres, lengua, música y danzas. El proceso civilizador ha dejado profundas huellas que hoy vemos en las sociedades campesinas. Además, su dimensión subcontinental no solamente ha permitido desarrollar un gran imperio en los Andes, sino también sostener por más de cuatrocientos años la administración colonial y mantenerse vigente al servicio de las comunidades campesinas contemporáneas (Castro 2004: 41). El Qhapaq Ñan ha jugado un rol importante en la historia andina, nunca ha perdido su misión integradora y articuladora, tanto en el tiempo uniendo el presente con el pasado, como en el espacio vinculando las poblaciones y ecologías. Esa fuerza histórica y cultural del Qhapaq Nan ha sido el pivote estimulante en la preparación de la exhibición.

La tarea de organizar la exhibición fue grande y compleja, haciéndose eco de la naturaleza de la infraestructura vial. En este sentido, sabemos que el Qhapaq Ñan gozó de gran protagonismo en el Estado Inka, y ello se quiso reproducir en la sala de exhibición. Tratamos de entender el antiguo camino en sus diversas expresiones, significados y simbolismos, para lo cual acudimos al registro arqueológico, al testimonio de los usuarios quechuas y aimaras contemporáneos y a la información histórica. Apelando a la moderna tecnología electrónica, preparamos maquetas virtuales, interactivos mecánicos y pantallas informativas. Con esos auxiliares electrónicos, pretendimos llevar a los visitantes por viajes imaginarios por las cuatro regiones o suyus, los diversos pisos ecológicos y la pintoresca y agresiva geografía andina; asimismo, a través del sistema de transporte exploramos algunas facetas de la historia inka, la estructura del Estado y el vasto territorio del Tawantinsuyu. Se mostró al camino como agente integrador de geografías y poblaciones, al unir la costa con la sierra y la selva, y al articular los valles con los altiplanos en una relación de verticalidad.

\section{¿QUÉ FUE EL QHAPAQ ÑAN?}

El sistema vial inka es el monumento más grande en la arqueología americana, una obra de ingeniería de grandes proporciones de la América preindustrial. Los segmentos del camino que 


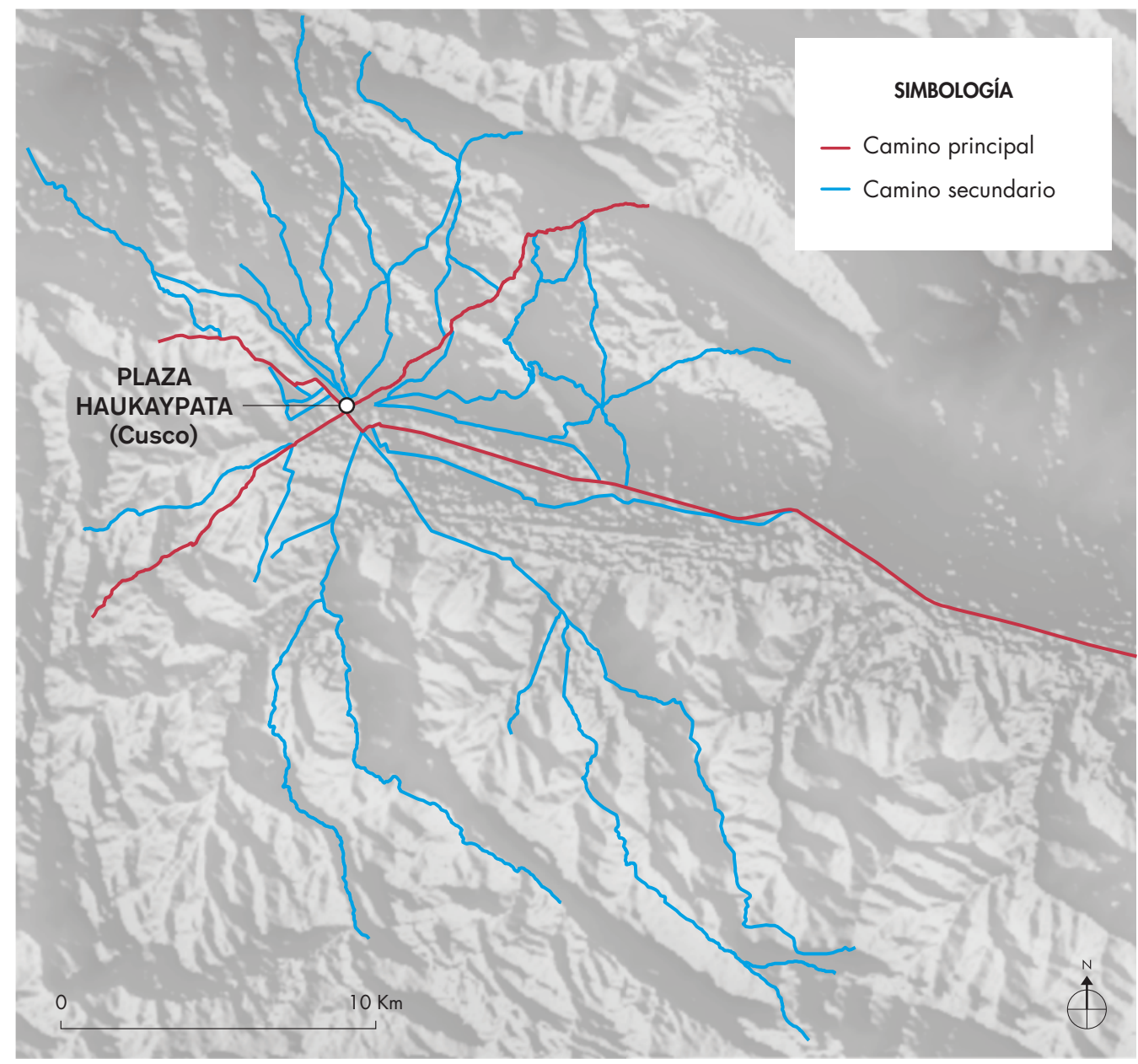

Figura 1. Mapa actualizado del sistema vial inkaico. Figure 1. Updated map of Inka Road system.

resistieron al tiempo siguen impresionando al visitante por su monumentalidad, la tecnología constructiva y el perfil que muestra sobre el paisaje andino. Observado panorámicamente, luce imponente, invitando a reflexionar sobre las estrategias para dominar una de las geografías más complejas del planeta sin el auxilio de sofisticados instrumentos. El camino atraviesa desiertos costeros y la cadena montañosa de los Andes, uniendo la cuenca del Pacífico con la alta Amazonía y los Andes septentrionales con los meridionales (Hyslop 1984). De esta manera, ha articulado la gran diversidad de ecologías del territorio andino, así como la diversidad de poblaciones asentadas sobre él, ayudando a la formación de la tradición en la cultura andina. Estratégicamente, esta red vial permitió integrar la diversidad de ecologías y grupos étnicos a una administración centralizada.

En poco tiempo, los inkas construyeron un poderoso imperio, similar a cualquier otro de su época, con gobierno centralizado en la capital, el Cusco, y una gran red de caminos que le 
permitía articular fluidamente con los gobiernos provinciales. La estructura del Estado estaba apoyada por instituciones administrativas y una burocracia jerarquizada expandida por todo el territorio. El imperio tenía una iglesia bien organizada, ejército, centros de enseñanza, etc., sobre cuyas instituciones el profesor John Murra destacaba "dentro de los modelos occidentales es difícilmente inteligible, imaginar un estado imperial sin mercado, sin moneda, sin transacciones comerciales basadas en oferta y demanda como los mercados occidentales, sin escritura convencional" (Murra 1975: 207).

El Estado Inka no tenía un régimen tributario en bienes o moneda, pero disponía del servicio obligatorio llamado mit'a, una forma de tributo en trabajo, mediante el cual el Estado recibía trabajadores especializados que se desplazaban por todo el imperio para cumplir con su servicio. El trabajo se organizaba de acuerdo a la agenda político-administrativa y con atención al calendario agrícola. Se dice que el Inka salía en campaña después de las cosechas y volvía para la siembra. El trabajo público se ejecutaba durante los meses de sequía y solo los especialistas entrenados para un oficio permanecían todo el año en su taller. Estos profesionales llamados kamayuq estaban exceptuados del servicio de mit'a. Guaman Poma (1980 [1615]) describe como quiro camayoq al carpintero, rumita chicoc al picapedrero, pirca camayoc al albañil, etc.

El Estado planificaba las obras tomando en cuenta las necesidades y los especialistas a disposición. Una de las obras prioritarias habría sido la construcción y mantenimiento del Qhapaq Nan. Es obvio, la red vial debía estar en perfectas condiciones para atender las funciones del Estado. El camino no solamente unía los centros administrativos, de redistribución y de almacenaje, sino también los campos agrícolas, plantaciones de coca, reservas de guano, yacimientos mineros, centros de producción y muchos otros más (Murra 1975: 23).

Durante el gobierno inka, el servicio de mit'a aseguraba que la materia prima, como la lana de camélidos de la puna, el guano en la costa, madera de la selva, etc., llegara a tiempo y en cantidades suficientes a los centros de producción, las cosechas a los centros de almacenaje, las colcas y lugares de redistribución. La energía que los mitayos entregaban al Estado era también una forma de interacción social llamado ayni o reciprocidad. Se trataba de prestaciones recíprocas de servicios. El poder político en los Andes se basaba en la redistribución, una acción avanzada en la interacción humana, un nivel amplio y genérico de reciprocidad (Murra 1975, 2002; Pease 2004). El poder inka se materializaba en la fuerza del ayni como prestación de servicios, movilizando miles de trabajadores por todo el territorio para cumplir con la mit'a y lealtad.

Los caminos cumplían funciones culturales, sociales y cosmológicas, conectando lugares y gente. Estos no se desplazan al azar, sus trazos y construcciones no son casualidades, pues obedecen a criterios estratégicamente planificados desde la sociedad. El sistema de caminos constituye el "nervio motor" en la actividad cotidiana de los pueblos, enraizando sus costum- 
bres y la rutina diaria. Para cientos de comunidades indígenas asentadas en los Andes, acaso los mismos caminos preinkaicos siguen sirviendo ahora como antes, con la misma vitalidad, "llevando" gente y bienes de un lado a otro. Metafóricamente hablando, el camino es la hebra de un tejido que entrelaza un pueblo con los otros (Erickson 2000). En ese universo, para las comunidades indígenas de antes y de ahora, el camino es parte de su cosmología, tiene vida y espíritu, convive con la gente. Esta fuerza real del Camino Inka es lo que se trata de mostrar en la exhibición. La historia oral ha sido elocuente para entender la vitalidad del Qhapaq ñan a través del tiempo, aunque no siempre es fácil ilustrarla en una sala.

\section{ORGANIZACIÓN DE LA EXHIBICIÓN}

El diorama está organizado en once secciones. Tratamos de mostrar el sistema vial andino desde las perspectivas sincrónica y diacrónica. El visitante debe conocer que la red de caminos en los Andes no es solamente obra inka. Tratamos de ofrecer información suficiente para identificar a los inkas en el tiempo y espacio, así como la historia del camino como parte de la historia de la civilización andina. Presentamos el sistema vial como parte del proceso histórico cultural. En la cronología de las culturas preoccidentales, los inkas están presentes en un corto período: 1400-1532 DC. Después del episodio de Cajamarca y la muerte de Atahualpa, el Tawantinsuyu fue destruido, el camino perdió su status político, mas no su religiosidad, ni sus funciones para el transporte, comunicación e interacción.

Consistente con la metodología y los principios que impulsa el NMAl, tratamos de destacar la información etnográfica y la historia oral que cuentan los líderes nativos quechua y aimara, usuarios contemporáneos del camino. En tal sentido, entendemos el Qhapaq Ñan desde una perspectiva etnoarqueológica. En líneas siguientes explicamos el contenido por secciones.

\section{Introducción}

Muestra fotos del paisaje andino y unas palabras del Secretario del Smithsonian, Dr. Wayne Clough, como introducción y mensaje. Clough compara el costo de una autopista moderna de los Estados Unidos con lo que habría costado la habilitación del Camino Inka. Un flyover muestra la red de caminos desde el aire.

\section{Los ancestros}

Presenta cuatro emblemáticas culturas pre-Inkas: Chavín (primer milenio AC); Tiwanaku, con su centro de poder a orillas del Lago Titicaca; Wari en Ayacucho, sierra central del Perú; y Chimú, en la costa norte del Perú, cuya capital Chan Chan fue la ciudad más grande del hemisferio occidental en su momento (siglos XII-XIV). Las tres primeras culturas vivieron una expansión panandina, mientras que la Chimú hizo lo propio por los valles de la costa norte peruana, con 
asentamiento y templos en diversos lugares. Estos movimientos implicaron la obvia existencia de caminos, sobre algunos de los cuales los inkas construyeron otros mejores. Mencionamos también a los antecesores inmediatos de los inkas en Cusco: Killke y Ayarmaca.

\section{Mitos de origen}

De los dos mitos más conocidos sobre el origen de los inkas, escogimos el de la pareja de esposos-hermanos: Manco Capac y Mama Ocllo, que salieron del lago Titicaca, enviados en peregrinaje por el padre Inti (Sol), con la misión de fundar una ciudad sagrada y civilizar a las gentes. Manco es el primer Sapa Inka en la dinastía de trece. Durante el viaje de Titicaca a Acapana (nombre del valle de Cusco antes de los inkas) habilitó el primer camino. Una pantalla con dibujos animados narra el mito en la voz de una niña ecuatoriana.

\section{Cusco}

Chawpi o Centro. Cusco fue fundado a comienzos del siglo xvı por Manco Capac, en medio de un valle fértil (Urton 2004). El noveno monarca, Pachacutec Inka (1438-1471), después de triunfar sobre los chankas, transformó la ciudad imponiendo un nuevo orden, físico, social y cosmológico. La ciudad tiene la forma de un puma, con el perfil del cuerpo delineado por los ríos Tullumayu y Saphy, la cabeza en Saqsaywaman, la panza es la plaza Hawkaypata, el chawpi o centro de la ciudad, y la cola formada por la unión de los dos ríos, llamado Pumachupan (cola de puma) (Betanzos 1968 [1551]: cap. XVII). La residencia de las panacas (familias reales) se encontraba dentro de la silueta del puma. La ciudad estuvo dividida en dos secciones: Hanan Cusco (Cusco de arriba) y (L/R) Hurin Cusco (Cusco de abajo). La división tenía siginificado físico, ideológico y social. Los primeros cinco Inkas pertenecían a (L/R) Hurin Cusco y los siguientes a Hanan. El eje imaginario este-oeste cruzaba por el Hawkaypata, el cual estaba cortado por otro de norte a sur, dando inicio a la formación de los cuatro cuadrantes del Tawantinsuyu, el territorio de "cuatro regiones unidas". La plaza era el chawpinpa chawpin (centro del centro). Los dos suyus: Chinchaysuyu y Antisuyu correspondían al hanan y los otros: Collasuyu y Contisuyu al (L/R) hurin. El relevamiento isométrico y el 3D de la ciudad inka fueron hechos por Ricardo Mar y Alejandro Beltrán (Alfaro et al. 2014).

Cusco fue la capital del Tawantinsuyu, el centro de poder y de gobierno inka, el chawpi del universo inka, popularmente llamado "ombligo del mundo". Como cualquier capital de imperio, Cusco fue construido para la administración del Estado, la burocracia administrativa, clero, ejército y servicios públicos. Susan Ramírez (2005) menciona que bajo el Estado Inka, Cusco denotaba al Inka, así como el Inka denotaba al Cusco, uno era el chawpi físico, espacio fijo, y el otro el chawpi movible. La persona del Inka encarnaba el chawpi.

De cada cuadrante de la plaza Hawkaypata salían tres calles, las cuales se juntaban al llegar a la puerta de salida del valle. En cada salida había una "puerta" con gran visibilidad y 
significado político-religioso. La que conduce al Chinchaysuyu se llama Titi Tica, la cual fue transformada en la Colonia, construyendo arcos sobre los muros inkas. Por ser la vía que conduce a Lima, el sitio conserva sus funciones hasta la actualidad, es un lugar de despedida y bienvenida a la vez. La puerta que conduce al Collasuyu se llama Rumicolca, está conservada; la que sale a Antisuyu es Yuncaypata, en referencia a la selva (yunca/yunga significa "selva alta"). La puerta que conduce al Contisuyu prácticamente ha desaparecido.

En Cusco había otros caminos religiosos llamados ceques, los cuales salían del templo Qoricancha. Hubo 41 ceques organizados en grupos de tres (tríade). Los tres suyus mayores: Chinchaysuyu, Antisuyu y Collasuyu, tenían 9 ceques, mientras que el pequeño, Contisuyu, contaba con 14. La organización tripartita funcionaba también como principio organizador, generacional y social. Collana es el principal, más antiguo, y Cayao el lado opuesto, quedando Payao como intermedio. Los autores también sugieren que la organización de los ceques tenía funciones calendáricas, con indicación de jerarquías generacionales (Baver 2000: 40; Zuidema 2010: 759).

Alrededor de la plaza Hawkaypa se encontraban los recintos públicos, palacios como la Cassana, atribuido como residencias de Pachacutic (Garcilaso) y Huayna Capac (Pedro Pizarro), Qora Qora (Tupac Inka Yupanqui), dos kallankas o"galpones" para reuniones públicas, un edificio en forma de cubo llamado Sunturhuasi. Luego continuaban otros aposentos como el Acllawasi, Amarukancha, Kusicancha y muchos otros (Farrington 2013), agrupados en doce barrios descritos por Garcilaso (Rostworowski 2009: 74). Las residencias estaban organizadas en torno a un patio cuadrangular, rodeado de recintos, por lo que se les llamaba kancha. La ciudad estaba ordenada en parcialidades reales y no reales. Los cronistas de la Colonia nos han dejado profusa información histórica sobre Cusco.

La plaza tenía dos secciones: el Hawkaypata (andén de fiestas) y el Kusipata (andén de alegría). En medio de la plaza había una fuente de agua, donde se bañaba el dios Illapa o Trueno, considerado hermano de Pachacutic. Destacaba el ushnu, un altar piramidal dedicado a Inti, sobre el cual había una wanka o piedra cilíndrica. El sol de los inka tenía forma humana. El suelo de la plaza estuvo cubierto con arena llevada del mar, sobre la cual "plantaron" vasos de oro y plata, estatuillas de alpaca, llama, felino y hombres, esculturas de piedra, oro, plata y mullu, algunos de tamaño natural.

Para ingresar a Cusco había que cumplir con un ritual y pedir permiso para transitar sobre su suelo. En la exhibición presentamos a Demetrio Roca Wallparimachi, de 94 años, rezando en quechua antes de ingresar a Cusco, ritual que repite desde su infancia, cuando llegó por primera vez con su madre en 1928. Zuidema cuenta que cuando llegó por primera vez a Cusco en 1960, sus compañeros de viaje le obligaron bajar del vehículo para orar y cumplir con el ritual. 
Para una mejor visualización del Cusco, se ha montado una maqueta electrónica con varios accesos pulsando señales. El visitante puede ver, escuchar la narración y tener una mejor experiencia sobre detalles de los recintos emblemáticos, como el templo Qoricancha, el centro administrativo de Kusicancha, Saqsaywaman, Hawkaypata, residencias, etc. La maqueta es ampliada con isométricos en 3D, los cuales muestran la división Hanan (arriba) y (L/R) Hurin (abajo), la fisonomía original de la ciudad, con residencias construidas sobre andenes y el plano de la ciudad con terrazas que se suceden desde el fondo del valle llamado Angostura hasta Saqsaywaman, sobre las cuales edificaron los grandes aposentos o kanchas. Algunos de esos andenes todavía son visibles, otros quedan en la memoria de los ancianos que los recuerdan. Con la introducción de la rueda, primero con las carrozas de la Colonia, luego los vehículos motorizados, los andenes fueron aplanados, quedando muy pocos in situ. Con los testimonios recogidos, podemos afirmar que Cusco fue transformada dramáticamente en los últimos 70-80 años. Los ancianos recuerdan con nostalgia los andenes, calles y casas inkas. Fue interesante hacer etnografía en la ciudad y escuchar las historias orales. Fuera del área ocupada por la silueta del puma, en la periferia, se encontraban las viviendas de los mit'ayoq, jornaleros que acudían a Cusco para cumplir con su obligación de tributo y de las guarniciones militares.

En esta sección mostramos objetos originales inkas, en oro, plata, aríbalos, quipus, mullu (Spondylus princeps), una hermosa túnica con decoración de tukapu de la colección de Dumbarton Oaks y otros objetos imperiales.

Para el valle del Cusco, la exhibición se ha beneficiado con la investigación de Donato Amado sobre caminos sagrados y seculares. En este trabajo, Amado incluso ha podido identificar al autor de alguno de los caminos, como por ejemplo el "camino viejo del Inka", atribuido a Pachacutic, así como los caminos que fueron marcadores de dos suyus, etc. (fig. 2).

Rostworowski (2009: 89) ofrece otro dato para Pachacamac, señalando que "existían cinco caminos que cruzaban Pachacamac de norte a sur, los cuales correspondían a diferentes grupos de pobladores según sus oficios: sabemos que el quinto correspondía a los chasquis, mensajeros incaicos, portadores de noticias, era el camino que bordeaba el mar. El cuarto correspondía a los pescadores, servía para el trajín del pescado. Se desconocen las funciones especiales de las otras rutas". Citando a Gutiérrez de Santa Clara, Rostworowski (2009) señala que en Collasuyu había tres caminos, el del medio era para uso del Inka. En la actualidad se reconoce en la cuenca del Titicaca dos ramales del camino: Uma y Urqo.

\section{Expansión y conquistas}

De los trece Inkas de la dinastía, los cinco primeros son considerados mitológicos y los demás históricos. De estos últimos, solo tres fueron conquistadores, que expandieron el territorio del Tawantinsuyu hasta la extensión que conocemos, Pasto en Colombia por el norte, río Maule 


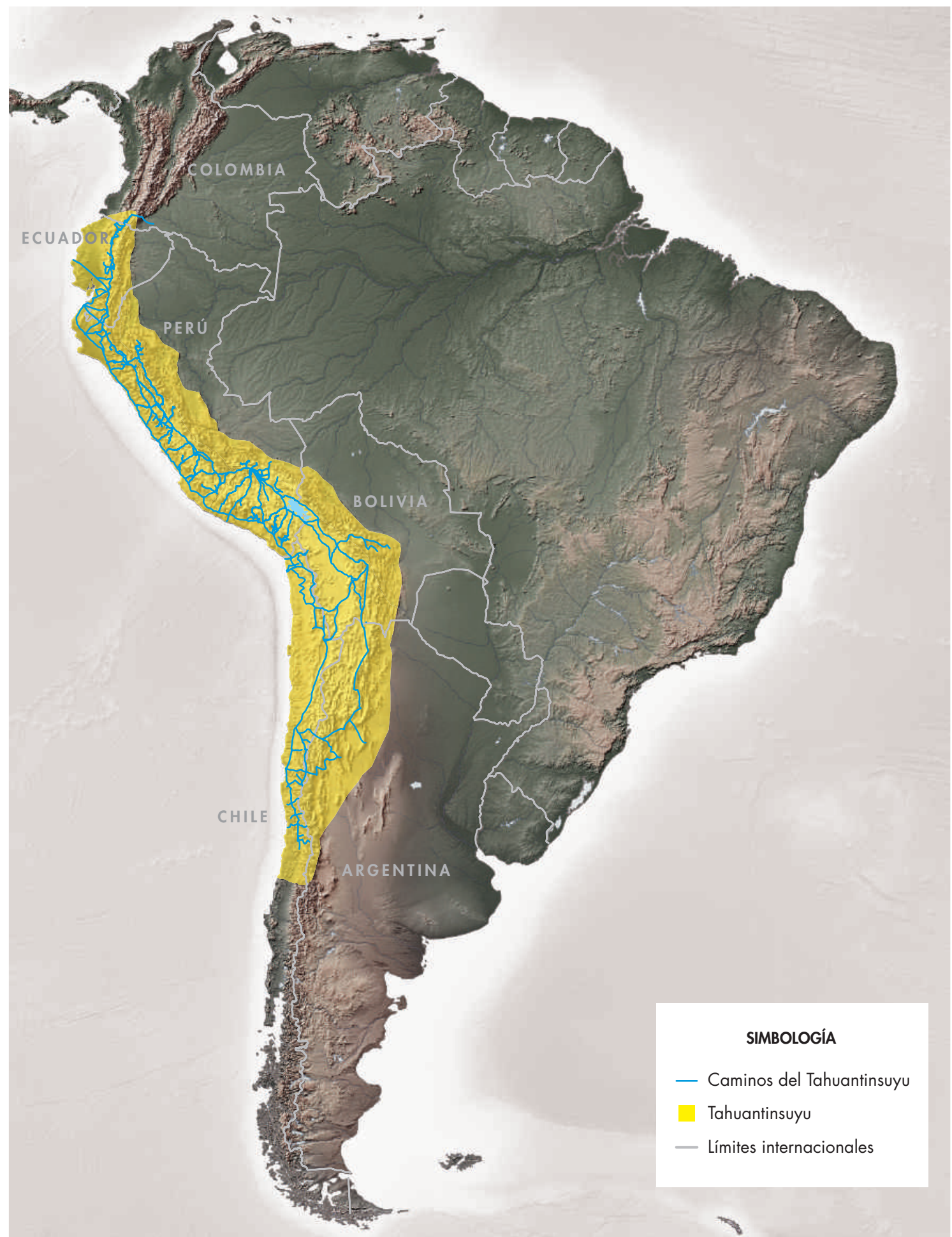

Figura 2. Mapa con los caminos del Tahuantinsuyu. Figure 2. Map of Tahuantinsuyu roads. 
en Chile por el sur, la ceja de montaña por el oriente y el Océano Pacífico por el occidente. Los Inkas guerreros fueron Pachacutec, Tupac Inka Yupanqui y Huayna Capac.

Exploramos los objetivos de la expansión y conquista inka, particularmente la misión religiosa, la difusión del culto al Inti, la construcción de ushnus por todo el Tawantinsuyu y los peregrinajes, algunos de ellos vigente en la actualidad, como el caso de Qoyllurit'i en Cusco. Así mismo se menciona, como objetos de la expansión, el acceso y apropiación de las tierras de cultivo y pastoreo, agregando nuevas haciendas al Estado y la iglesia, la explotación de los recursos mineros, el oro, la plata, cobre, salineras, así como las plantaciones de coca, plantas medicinales, el mullu en la costa de Guayaquil, mopa mopa en Putumayo, Colombia, etc. Por supuesto, el recurso más importante fue el acceso a la mano de obra, enrolando a los expertos para llevarlos al Cusco como instructores en los centros de entrenamiento y producción, y los demás, jefes de familias censados en cada comunidad, para cumplir con el servicio de mit'a.

Pachacutec, "transformador del mundo", fue el Inka visionario: reordenó el Cusco y expandió el territorio del Imperio hasta Conchucos y Cajamarca. Impulsó la agricultura en la región de Chinchaysuyu hasta los reinos altiplánicos del Collasuyu, donde fomentó también la ganadería y buscó el acceso a los recursos mineros. Tupac Inka Yupanqui continuó con las campañas iniciadas por su padre y llegó a conquistar a los cañares, los caranques, los mantas y los huancavilcas, asediando también al reino Chimor, el señorío Ishma o Pachacamac y el reino de Chincha con su templo Chinchaycamac (estos últimos sometidos mediante la diplomacia). Por el Qollasuyu consolidó el dominio sobre los reinos aimaras y continuó hacia la región diaguita hasta el río Maule. Por la sierra avanzó a Cochabamba en Bolivia, Juyuy, la Quebrada de Humahuaca, y luego hasta las provincias modernas de Mendoza y Córdoba en Argentina. En esos territorios se benefició de las minas de oro, plata, cobre y plomo. El período de Huayna Capac se caracterizó por las rebeliones, varias nacionalidades descontentas con el gobierno del Cusco se sublevaron. El Inka se dedicó a pacificar a los grupos alzados, por lo cual sus conquistas agregaron escasos territorios al imperio. Murió en Quito poco tiempo después, afectado por la viruela (fig. 3).

Durante el gobierno inka se crearon talleres exclusivos para producir objetos para el Estado y la iglesia. Se trataba de bienes dedicados al uso y servicio del Inka, las panacas, el sacerdocio, los templos y espacios sagrados. Fabricaron objetos estandarizados con el mismo patrón decorativo y forma. Unos fueron producidos en Cusco y otros en provincias. A los primeros se les conoce como estilo inka imperial y los segundos como estilo inka provincial. Estos últimos no dejan de expresar la tradición de su cultura ancestral propia. En tal sentido, en la cultura material inka son muy conocidas la cerámica, tejidos kumpi, objetos en oro y plata repujado, estatuillas en cerámica, oro, plata y cobre, los cuales repiten el mismo perfil de cuerpo, cara, tratamiento, tanto en efigie de animales como humanos. El patrón de diseño decorativo y la manufactura se reproduce como si fuera fábrica de símbolos oficiales. 


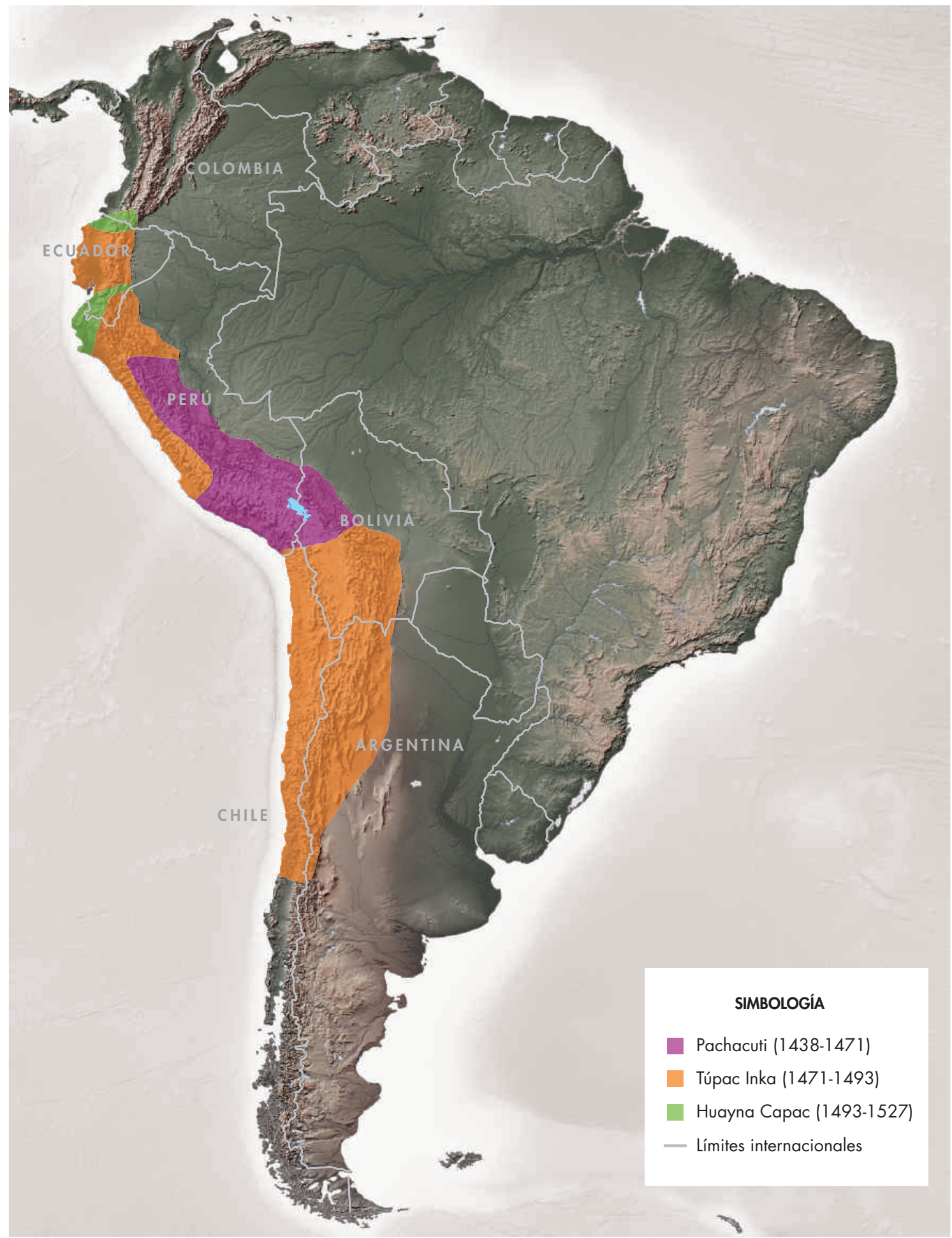

Figura 3. Mapa de las conquistas inkas. Figure 3. Map of Inka conquests. 
El Estado administraba grandes y óptimos centros de producción en Cusco y en las cabeceras de provincias, donde funcionaban talleres con experimentados maestros y trabajadores, así como las acllawasi, lugares donde vivían las mujeres escogidas, dedicadas exclusivamente a producir finos tejidos kumpi y otros objetos para el Inka y su familia, el sacerdocio y los templos. En esos talleres obviamente producían objetos de alta calidad, repitiendo el mismo patrón regulado por la administración. Esos objetos eran transportados por el Qhapaq Nan de un lado a otro, de Cusco a las provincias, generalmente como donaciones a los señores étnicos y para ofrendas a las divinidades locales.

Mientras era notable la producción estandarizada de objetos muebles, no ocurría lo mismo con la edificación de nuevos asentamientos. La planificación y construcción de las nuevas instalaciones, aunque respondían a un "urbanismo obligado", como señalaron Morris y von Hagen (1993) y Hyslop (1990), no repetían el modelo de Cusco, aunque se preocuparon por construir los edificios emblemáticos del Estado, como la kallanka, el acllawasi, las colcas, la plaza, el ushnu, etc., sin copiar necesariamente el plano de la ciudad prototipo. Más bien, el registro arqueológico revela que las nuevas instalaciones se adecuaban a la topografía del suelo y la magnitud de la provincia. Tienen la apariencia de Cusco, pero ninguno es copia o igual a la ciudad capital. Hyslop (1990), durante su recorrido por las provincias de Tawantinsuyu se dio cuenta de este hecho, señalando que no existen dos asentamientos inkas iguales.

Durante nuestro recorrido por los cuatro suyus, nos dimos cuenta de otro detalle importante, el cual dejamos para futuras investigaciones. La construcción con sillar labrado, de estilo Cusqueño, fue difundido hacia el Chinchaysuyu, mientras que está casi ausente en el Collasuyu. Existen edificios de sillar en lugares remotos como Caranque, San Agustín de Cayos, hasta Rumichaca en Ecuador, el cual es débil o ausente en Collasuyu a pesar de tener la tradición de Tiwanaku. En Antisuyu hay algunos ejemplos en Vilcabamba y Chachapoyas, mientras que en Contisuyu su presencia es muy débil. Otro caso que merece estudiarse es la práctica de la capaqucha, los entierros de ofrendas humanas en altas montañas, los cuales al parecer son más frecuentes en Collasuyu y Contisuyu y están casi ausentes en el Chinchaysuyu, con excepción del hallazgo de una capaqucha en la isla de Puná, frente en la costa de Guayas. Al respecto, no hemos encontrado noticias sobre el Antisuyu.

\section{LOS CUATRO SUYUS DEL TAWANTINSUYU}

El diorama incluye los cuatros suyus del Tawantinsuyu individualizados. El objetivo es mostrar las características geográficas, económicas, culturales y sociales de cada suyu, en tanto que ellos tienen sus propias particularidades, ninguno es igual al otro. Además, consideramos necesario que el visitante entienda que los cuatro suyus no están identificados literalmente con los cuatro puntos cardinales, como ocurre en otras culturas indígenas. En los Andes, estos asumen una connotación mucho más amplia. El Chinchaysuyu es el área septentrional, el Collasuyu es la 
meridional, el Antisuyu se identifica como el oriente y el Contisuyu como occidente, cada cual con potenciales recursos y paisajes particulares.

Aprovechamos estas secciones para mostrar algunos casos de estudio sobre ingeniería inka, como la tecnología empleada en la construcción de caminos, de puentes, manejo de aguas, inclusive las estructuras asociadas como tambos, lugares para alojamiento, colcas, centrales de almacenaje y los trabajos complementarios para la conservación. Presentamos el Qhapaq Ñan en su contexto, como una infraestructura con servicios, acompañada de facilidades, una ruta de viaje confortable. La construcción del camino necesariamente conllevaba la edificación de servicios para la comodidad del viajero. Los ingenieros inkas previeron estos hechos prácticos, especialmente para viajes de larga distancia. Por eso, construyeron aposentos para los viajeros con servicios básicos, como habitaciones para dormir, corral para ganados, cocina, servicio de agua, etc, a los cuales llamaron qorpawas, una especie de hostal. Igualmente habilitaron tianas, pascanas o descansaderos, apachetas o lugares de ofrenda, los chaskiwasi, caseta instalada como posta para el chaski.

El nombre de los hospedajes, qorpawasi, muy pronto después de la invasión española se ha perdido, posiblemente en parte por su ubicación en la entrada a las instalaciones administrativas o centro provinciales, como Tarmatambo, Xauxatambo, Limatambo, etc., siendo remplazados con el nombre general de tambo o tampu.

Quisimos que la exhibición diera cuenta del ingeniero de caminos en acción, con ejemplos concretos en los que soluciona los desafíos impuestos por las diversas topografías. En este aspecto, los usuarios contemporáneos ofrecen interesantes informaciones. Por ejemplo, hemos observado que los constructores modernos acuden con frecuencia al sentido común, no siguen una regla que repiten mecánicamente, que se aplica tanto para el uso de recursos (piedra, madera, fibra, etc.), como para la experiencia humana. Los habitantes de un lugar conocen mejor que nadie su medio, están familiarizados con las fluctuaciones climáticas, naturaleza del suelo, la textura de las rocas y piedras, la flora y fauna; sin duda, están habilitados para ejecutar trabajos de gran envergadura. El puente colgante de Qeswarchaka, por ejemplo, es construido con ichu de puna, porque tienen este recurso, mientras que en Sarhua, Ayacucho usan la pajpa o cabuya.

Hemos tratado de entender el sistema de caminos en el Tawantinsuyu, en sus diversas características y tecnología, para poder mostrarlo en la exhibición y compartirlo con los visitantes, pero esto no fue tarea fácil. Intentamos inclusive hacer una tipología de caminos dentro del sistema del Qhapaq Ñan; la tarea fue muy compleja. La experiencia aprendida fue que así como no existen dos instalaciones inkas iguales, tampoco hay dos porciones del camino iguales, aunque en ambos casos se repiten ciertos patrones, inclusive determinadas tecnologías, como el empedrado, uso de marcas como las sayhuas, las apachetas, etc. Hemos apelado a las pioneras publicaciones de Hyslop (1984) y Vitry (2000), entre muchas otras que describen el camino e intentan ordenarlos en grupos. Obviamente nos hemos beneficiado con algunos 
reportes de los colegas que trabajan para el expediente de la UNESCO, pero confesamos que no hemos logrado un didáctico ordenamiento desde el punto de vista de la ingeniería, a pesar del excelente registro arqueológico existente. La multiplicidad de relieves topográficos, nichos ecológicos, climas y condiciones del suelo obligaron a los constructores a acudir a soluciones locales, con respuestas singulares para cada caso, cuidando la armonía y la integridad del paisaje. Sintetizar el mosaico de hechos y datos que presenta el Qhapaq Ñan para una exhibición es materialmente imposible.

En las áreas agrícolas de los valles de la costa, por ejemplo, el camino es formal, con anchas avenidas encerradas en muros de tapia a ambos lados, canales de drenaje y cunetas, terraplenes o calzadas con elevación y muchas veces empedrados. Estas avenidas son generalmente ingresos a grandes asentamientos o ciudades, como Chincha, Pachacamac, Tambo Colorado, Chan Chan, Puerto Inka, por mencionar solo algunos. Inclusive existen citas tempranas como la de Cieza (1962 [1553]: 182) quien señala que "el camino costeño era una gran realización, aunque menos difícil de construir que el Camino Inka principal de la sierra". Los grandes desiertos no fueron cruzados por el Camino Inka, estos atravesaban cerca de las estribaciones o por el Chawpiyunga, por donde generalmente existen ojos de agua.

En terrenos con gran humedad, como los altiplanos o zonas humedales, construyeron el rasante en plataforma, una especie de vereda, con suficiente elevación para evitar la humedad permanente o estacional en el rasante. Estos tramos generalmente son cortos. Tomaron las previsiones necesarias para las descargas de lluvias y deshielos estacionales. En otros casos como Cajamarca, Huánuco Pampa y Cusco, empedraron el rasante con grandes adoquines debido a las condiciones el suelo. Cobo escribe el tramo de Chucuito: "como va el camino real por la ribera de la laguna de Titicaca, cuando ella crece en tiempo de aguas, añega el contorno del camino, y solo la calzada queda descubierta y por ella se camina, cubriendo el agua la tierra por un lado y otro, unas veces medio estado y otras más. Por debajo de estas calzadas hay sus caños y desaguaderos, con sus portazuelas hechas de grandes lozas, por donde corre el agua de unas partes a otras sin detenerse ni rebosar" (Cobo 1964 [1653]: 128- 129). Existe otro igual para la pampa de Anta en Cieza (1962 [1553]: 240-241).

\section{Chinchaysuyu}

Es la región ubicada al norte de Cusco, ocupada actualmente por las modernas repúblicas Perú, Ecuador y sur de Colombia. Chinchaysuyu fue "la ruta hacia Chincha o Chinchaycocha" (Julien 2012). Chincha era un gran señorío, asentado en la costa central peruana, al sur de Lima. Sus habitantes fueron expertos tejedores y grandes navegantes. Los balseros que se cruzaron con los españoles frente a la costa de Guayas fueron precisamente los chinchanos. Aunque Chinchaysuyu fue un territorio con gran variedad de recursos naturales, se destacaba por ser región agrícola, la cual fue reconocida por los cronistas y el registro arqueológico. Desarrollaron sistemas de riego en los valles de la costa y de la sierra, construyeron andenes 
y bancales para ampliar las fronteras agrícolas, se preocuparon por conservar el medio ambiente, protegiéndola de la erosión y la desertificación.

Los cronistas de la Conquista y la Colonia no dejaron de expresar sus sorpresas por la cantidad de colcas llenas de comida y otros bienes encontrados en el norte, así como por la calidad de los caminos, comparables con los romanos. Hyslop (1984) ha observado que los viajeros del siglo XVI evaluaron las características constructivas, secciones pavimentadas, bellas escalinatas construidas y/o talladas en piedra de los caminos del Chinchaysuyu asociados a tambos y centros administrativos principales, llamados algunos de ellos Segundos Cuscos.

Chinchaysuyu se extendía hasta el territorio de los Pasto y el Putumayo al sur de Colombia. En esa región crecia el árbol llamado mopa mopa, cuya resina era utilizada para pintar y laquear los keros, el cual sigue en uso con el nombre de "barniz de Pasto". En Putumayo habitan los Ingas hasta la actualidad, hablan quechua y se identifican como mitimaes inkas y siguen transitando por el Qhapaq Ñan.

Hemos incluido dos casos de estudio en esta sección: el puente colgante de Qeswarchaka y la construcción de camino en una zona con fuerte humedad y precipitaciones fluviales, como Machu Picchu, donde el manejo de agua para conservar el camino es importante. Para el puente Qeswarchaka contamos con el apoyo y los estudios de John Oschendorf, professor del MIT, y para Machu Picchu con las meticulosas investigaciones de los esposos Ruth y Kenneth Wright (Wright et al. 2000).

\section{Antisuyu}

Es el suyu o ruta que se desplaza hacia la región anti o ceja de selva, la alta Amazonía. Anti significa foresta tropical, donde crece la coca y plantas medicinales, y donde habitan pájaros con exóticas plumas, el otorongo (jaguar) y, también por gente considerada como "no civilizada". Los inkas tuvieron muchas dificultades para asentar sus dominios sobre esta región, principalmente por ser endémica, con enfermedades como la malaria, fiebre amarilla, verruga, uta, etc. Las llamas no pueden permancer más de 3-4 días por el calor. Tomando en cuenta el significado lingüístico, cultural, las referencias coloniales y la evidencia arqueológica, consideramos como territorio del Antisuyu, el oriente del Tawantinsuyu, desde las tierras bajas de Bolivia (Chaco, Santa Cruz, Beni), oriente del Perú (Madre de Dios, Vilcabamba, Chanchamayo, Chachapoyas) hasta Ecuador y Colombia (Morona, Quijo, Sabandía, etc.). Es decir, el Antisuyu es la franja transandina, no se reduce al oriente del Cusco como se creía tradicionalmente. Como un caso de estudio presentamos la ruta de la coca, el camino de penetración de Cusco-Paucartambo-Cosñipata, aunque reconocemos el enorme valor que tuvo la ruta a Sonqo, en las yungas de Bolivia, sobre el cual existe una visita publicada por Murra (1991). La administración inka controlaba la producción, transporte y distribución de la coca, la cual se mantuvo durante la colonia hasta mediados del siglo xx. 


\section{Collasuyu}

Collasuyu significa "la ruta hacia el Colla o Collao". El altiplano del Titicaca se conoce también como Collao, habitado por los poderosos reinos aimara y puquina. Los habitantes de esta zona fueron por excelencia pastores y caravaneros. Aun cuando se distinguieron por desarrollar extensiva ganadería (llamas y alpacas), fueron también agricultores, principalmente de la papa, quinua y otros productos altoandinos. El Collasuyu es actualmente ocupado por las modernas repúblicas de Perú, Bolivia, Chile y el noroeste de Argentina. Qhapaq Ñan en el altiplano del Titicaca tiene dos ramales: uno atraviesa por el lado occidental y se llama Urqo, el otro por el lado oriental y se llama Uma, con el lago como centro o taypi. Esta composición dual empieza en el valle del Cusco y tiene profunda connotación cosmológica. En la región existen, además, grandes recursos mineros, de oro, plata, cobre, plomo, tungsteno, salares como los de Uyuni y Atacama (Berenguer 2009). Minas importantes como las de Potosí en Bolivia, Chuquicamata en Chile, entre muchas otras, ya eran explotadas desde la época inka. Como caso de estudio, destacamos los caminos construidos sobre terrenos pantanosos del Titicaca, las casas de hospedajes para los viajeros o qorpawasi, así como la producción de papa en Cochabamba, Bolivia.

\section{Contisuyu}

Es el suyu más pequeño pero el más sagrado. Saliendo el camino del Cusco, se desplaza directamente al occidente, sobre la vertiente occidental de la cordillera hasta las playas del Pacífico. Es la "ruta hacia la etnia conde". Los Conde fueron un importante grupo étnico asentado en la cuenca del Colca. En en valle de Cusco disponían de 14 ceques. Su territorio incluye una de las cordilleras más altas de los Andes, con volcanes como el Ubinas, el cañón del Colca, amplias y hermosas playas en el litoral, ubicadas entre Atiquipa en Arequipa hasta llo en Moquegua, con grandes recursos marinos, como el pescado, mariscos, qochayuyu (alga marina) y guano, así como el algodón nativo llamado pardo por el color, que crece en abundancia en los valles adyacentes. Como caso de estudio consideramos la construcción y manejo de colcas, centrales de almacenaje del Estado Inka, las cuales por extensión conceptual, se refieren también al cañón del Colca, como almacenaje natural de bienes de consumo. Una de las instituciones que marcaba diferencia con los españoles era la cantidad de colcas, llenas de comida, ropa, herramientas y muchas otras cosas (Cieza 1962 [1553]: caps. XLIV y LXXXIX).

\section{Colonial}

El imperio del Tawantinsuyu, construido con gran visión social por los inkas (siglos XV-XVI), un país con ambiciones de integración, con política redistributiva de bienes en todo el territorio, sin pobreza ni esclavos como los que había por aquel entonces en Europa, en pocos años fue desarticulado y destruido. Francisco Pizarro y sus 160 compañeros de aventura asaltaron Cajamarca, el 15 de noviembre de 1532, invitando con engaños al inka Atahualpa a una reunión. 
Luego que el Inka asistiera al encuentro, fue capturado y encarcelado. Para liberarlo exigieron un ambicioso rescate en oro y plata. El Inka cumplió con el rescate, pero igualmente fue asesinado.

Huayna Capac, el último Inka del Imperio tuvo dos hijos, Atahualpa con una princesa quiteña y Huáscar con su esposa cusqueña. Huayna Capac construyó una ciudad en territorio Cañar, a la cual llamó Tomebamba, nombre de su panaca, repitiendo los símbolos y edificios emblemáticos del Cusco (Rostworowski 2009: 119). Era un segundo Cusco. Huayna Capac murió infectado por viruela sin designar un heredero. La enfermedad tomó delantera a los españoles. Los dos hermanos, Huáscar y Atahualpa, no demoraron en enfrentarse en una guerra civil buscando el poder. Huáscar fue muerto cerca de Huánuco Pampa por los guerreros de su hermano. Mientras Atahualpa celebraba el triunfo, recibió la invitación de Pizarro, a la cual accedió sin imaginar el engaño.

Luego de la muerte de Atahualpa, el Imperio sucumbió, los templos fueron saqueados y destruidos, la población sometida a un nuevo orden político y social, obligada a practicar costumbres y creencias ajenas a las suyas. Ese episodio, conocido eufemísticamente como el "encuentro de dos mundos: América Indígena y Europa", ha producido el mestizaje cultural y biológico. La familia real inka fue empobrecida y las comunidades explotadas. Pizarro justificaba la conquista en nombre de la iglesia católica y los reyes de España. Fue una invasión de hombres blancos sobre nacionalidades indígenas. En la exhibición destacamos la transformación del mundo andino, el aniquilamiento de lo indígena para privilegiar lo occidental. La crónica de primer escritor y etnógrafo andino Felipe Guaman Poma de Ayala (1980 [1615]), es la fuente que usamos para mostrar el antes y después de Pizarro.

Muerto Atahualpa, los hermanos Pizarro marcharon sobre el territorio del Tawantinsuyu, uno a Pachacamac, uno de los ricos templos en la costa, otro a Cusco para capturar y desarticular la estructura política de gobierno y la administración del Estado. Unos meses después fundaron Xauxa (1533), como primera capital del gobierno español, la cual solo tuvo vigencia de unos meses. Luego fundaron Lima como capital del Virreinato del Perú, el 18 de enero de 1534, con la cual, Cusco fue desactivado. Lima es el nuevo centro de poder, Cusco pierde su estatus político pero nunca su ideología andina. Los españoles fundaron nuevas ciudades, generalmente en valles agrícolas, otras asociadas a minas, ingenios; también crearon pueblos para indios junto a reducciones y obrajes. Surgieron entonces ciudades como Charcas, La Plata, Quito, Huamanga, Santiago, Huancavelica, etc., entre otras. Para esta sección contamos con la asesoría de nuestra colega Carmen Arellano (2015).

La agricultura con plantas importadas y la crianza de nuevas especies de animales transformaron dramáticamente el paisaje andino. Sin embargo, los cultivos nativos y el pastoreo de camélidos se mantuvieron consistentes hasta la actualidad. Se formaron latifundios con trabajadores indígenas, surgieron los mercados con mercaderes y trajinantes, desarrollaron el comercio con sus actividades complementarias. Las carrozas españolas tuvieron uso limitado 
debido a la topografía andina, entonces el Qhapaq Ñan siguió siendo el sustento principal para el tráfico y transporte, muchos tambos abandonados fueron rehabilitados por orden de las nuevas autoridades (Glave 1989).

Durante la Colonia se introdujo el sistema de mercado, no obstante el intercambio de productos o trueque persistió, sin mediación de la moneda. Esta forma de transacción generalmente se llevaba a cabo entre bienes de un piso ecológico por otros, como la lana, charki, chuñu, tejidos de la puna por maíz, frijoles, fruta, coca de los valles, siguiendo el antiguo sistema de verticalidad andina. El sistema todavía se practica en la región sur andina. El transporte con caravanas de llamas todavía es vigente en la sierra andina del Perú y Bolivia. Algunas comunidades han remplazado o agregado las acémilas occidentales como bestias de carga, pero el camino sigue siendo el Qhapaq Ñan, a veces llamado "camino de herradura", en referencia a los herrajes del caballo.

Esta sección está ilustrada con objetos coloniales, por ejemplo, una manta del Titicaca, con imágenes religiosas, la cruz sobrepuesta sobre las apachetas, objetos vinculados a la caballería, fotografías mostrando la superporsición o imposición de construcciones españolas sobre las inkaicas, como el Qoricancha, cargando encima al convento de Santo Domingo.

\section{Camino vivo}

Después de la invasión española, el Qhapaq Ñan siguió dando su servicio, cumpliendo con su misión de transporte y comunicación, con la misma vitalidad de antes. Para las comunidades quechuas y aimaras contemporáneas, es parte de su universo, evoca la grandeza de los inkas, es el acompañante cotidiano del viajero y un legado histórico que une el presente con el pasado. Para ellos, el camino tiene vida, es "camino vivo". En tiempos modernos ha recibido diversos nombres: "Inka ñan", "Ñawpa ñan" o "Chaki ñan", "Ingañan", "chakiñaani", etc. En ciertos lugares se le reconoce como "camino real" o "camino del Inka", para diferenciarlo de los otros. Ciertos elementos asociados al Camino Inka se conservan, como la apacheta, la sayhua, el tampu y los espacios sagrados, la mayoría de ellos con una cruz católica encima.

Después de cinco siglos, muchas comunidades quechuas y aimaras siguen habitando los mismos asentamientos inkas, sembrando sus productos en las mismas chacras, usando los mismos canales de riego, tejiendo sus ropas con la misma técnica ancestral, hablando su misma lengua, practicando sus creencias dedicadas a la Pachamama, los apus y wamanis y transitando por el mismo Qhapaq Ñan. Se estima en 8 millones a los quechua hablantes y en un millón a los aimara. Ellos son los depositarios de la historia y la cosmología vinculadas a los caminos.

Muchos tampus inkaicos fueron abandonados después de la invasión española. Sin embargo, el nombre persiste aunque con significado original cambiado. El concepto de tambo estaba asociado a centros administrativos inkas, en los cuales obviamente existían lugares de aloja- 
miento y de servicios para el transeúnte, casas de hospedaje para viajeros o qorpawasi. Hoy existen tambuypata y tambowasi en algunas comunidades, que consisten en una habitación techada y un corral para los animales. A veces estos tampuwasi se encuentran dentro de una propiedad privada, pero cualquier transeúnte puede solicitar alojamiento. Los alojados retribuyen al dueño o administrador con un obsequio, que es una forma de ayni.

Para los nativos contemporáneos, el Camino Inka es un "camino vivo", con alma, espíritu y energía. Para los quechuas de Cusco, el camino es guía, "es el que lleva al transeúnte al lugar deseado", mientras que en la sierra central del Perú, "el Camino Inka acorta distancias". Reconocen que "caminar por el Camino Inka [...] no cansa". Los curanderos cañaris del Ecuador, kallawaya de Bolivia, mencionan al camino como depositario de energía, dicen que está presente el espíritu del Inka.

Entre tantos caminos que surcan los Andes, los restos del Qhapaq Ñan se pueden reconocer por la toponimia, como "inka tiana", "inka samana" o "inka jarana" en Bolivia, "paskana" en Chile (lugar de descanso), "inka pata", "inka chaka", "inka qawarina", "ñusta wayqo", etc. Sin embargo, de la multiplicación de caminos, los nativos pueden todavía reconocer el Camino Inka y diferenciarlo de los otros. La etnia Yumbo del Ecuador, por ejemplo, diferencia los coluncu del camino real, es decir, el Camino Inka usado en la Colonia.

En muchos lugares el Qhapaq Ñan está vinculado a lugares donde se desarrollaron las ferias, especios abiertos para el intercambio y comercio de bienes de consumo. Las ferias generalmente son semanales, otras anuales, estas últimas coinciden con la celebración del santo o santa patrón o patrona del pueblo. Desde la Colonia hasta la actualidad, en las ferias pueblerinas alternan la transacción con moneda y trueque. Los pastores de la puna llevan sus productos como charki, chuño y tejidos, para trocar con maíz, frijoles y otros que crecen en los valles.

Un hecho interesante que salta a la vista es el aprovechamiento que los ingenieros modernos hacen del Qhapaq Ñan. Con relativa comodidad, sobreponen las carreteras modernas sobre las inkaicas, tal como se ve en muchos segmentos de la Panamericana de la costa, que se desplaza del Ecuador hasta Santiago en Chile, la Ruta 40 o Camino Inka, la Calle Real del valle del Mantaro, en el altiplano de Junín, etc., (Matos 1992). Mientras en algunas partes el antiguo camino es aprovechado por los modernos, muchas comunidades andinas todavía siguen practicando las formas de trabajo inka, como la minka y la chuta tradicionales, con las cuales los comuneros conservan los caminos y canales de agua. Por el sistema de chuta, cada ayllu se obliga a conservar una sección del camino o canal de agua. El líder de la comunidad, llamado qollana, convoca para cumplir con la obligación.

El transporte con llamas, aunque limitado, es todavía vigente entre las comunidades de pastores de Perú y Bolivia. Los pastores de Canta y Huarochiri, en la sierra de Lima, por ejemplo, bajan a los valles de la costa, Cañete y Chancay, para trabajar en la cosecha, a cambio reciben 
maíz como pago. Las llamas son usadas para el transporte de la chacra a la casa del dueño. Los pastores de las punas de Cusco y Titicaca, bajan a los valles contiguos del oriente y occidente, en busca de coca, maíz, frutas y otros productos, prestar servicios, a cambio de recibir bienes como retribución. Muchos aimaras se desplazan hasta los valles de Tacna y Arica por la antigua ruta del Qhapaq Ñan. Fue interesante para nosotros, ver cómo grandes porciones del Camino Inka siguen sirviendo, incluyendo los espacios sagrados, los descansaderos y las apachetas (Núñez \& Nielsen 2011).

La exhibición concluye con algunos mensajes. Tratamos mostrar a la sociedad moderna, especialmente a la norteamericana, que en la América indígena hubo un gran Imperio llamado Tawantinsuyu, igual que otros de su época en el viejo mundo, el cual para su desarrollo y funcionamiento, disponía de un sistema vial bien organizado, el más extenso y rápido del Nuevo Mundo, con servicio de mensajería tan rápido como exigente, a cargo de los postas llamados chaski.

En la narrativa tratamos de enseñar la historia del Camino Inka, como parte sustancial de la historia de la civilizacion andina. A través del Qhapaq Ñan, los visitantes a la exhibición deben salir reconociendo que, los inkas además de los logros en la ingeniería de caminos, fueron también portadores de importantes productos para el consumo humano, como la papa, maíz, quinua, la lana y carne de alpaca, entre muchos otros. Esta riqueza lograda con "tecnología andina", muestra a la sociedad moderna, el ingenio, conocimiento y manejo que los andinos tuvieron de su medio ambiente, al punto de domesticar plantas y animales, al igual que otras civilizaciones, las cuales estamos compartiendo con los pueblos del mundo.

\section{REFERENCIAS}

Alfaro, C.; R. Matos, R. Mar \& A. Bettrán, 2014. El urbanismo inka del Cusco: nuevas aproximaciones. Arqueología y arquitectura en la capital del Tawantinsuyu. Cusco-Washington-Tarragona: Municipalidad de Cusco-Smithsonian Institution-Universidad Rovira I Virgili.

Arellano, C., 2015. From Inka Road to royal road: The Inka Road in the Colonial times. En The great Inka Road. Engineering an Empire, R. Matos \& J. Barreiro, Eds., pp. 141-148. Washington DC-Nueva York: National Museum of the American Indian-Smithsonian Books.

Bauer, B., 2000. El espacio sagrado de los Incas. El sistema de ceques del Cusco. Cusco: Centro Bartolomé de las Casas.

Berenguer, J., 2009. Chile bajo el imperio de los Inkas. Santiago: Museo Chileno de Arte Precolombino. Betanzos, J., 1968 [1551]. Suma y narración de los Incas. Madrid: Biblioteca de Autores Españoles, Atlas.

CASTRO, V., 2004. Riqueza y complejidad del Qhapaq Ñan: su identificación y puesta en valor. En Tejiendo los lazos de un legado Qhapaq Ñan-Camino Principal: hacia la nominación de un patrimonio común, rico y diverso, de valor universal, C. Caraballo \& N. Sanz, Coords., pp. 40-48. Lima: UNESCO.

Cieza de León, P., 1962 [1553]. La crónica del Perú. Madrid: Espasa Calpe. 
Сово, B., 1964 [1653]. Historia del Nuevo Mundo. Madrid: Biblioteca de Autores Españoles, Atlas.

ERICKSON, C., 2000. Los caminos prehispánicos de la Amazonía boliviana. En Caminos precolombinos.

Las vías, los ingenieros y los viajeros, L. Herrera \& M. Cardale de Schrimpff, Eds., pp.15-42.

Bogotá: Instituto Colombiano de Antropología e Historia-Ministerio de Cultura.

FarRINGtON, I., 2013. Cusco urbanism and archaeology in the Inka world. Gainesville: University Press of Florida.

GLAVE, L. M., 1989. Trajinantes: caminos indígenas en la sociedad colonial, siglos XVI-XVII. Lima: Instituto de Apoyo Agrario.

Guaman Poma de AyalA, F., 1980 [1615]. El primer nueva crónica y buen gobierno. México: Siglo XxI. Hyslop, J., 1984. The Inka Road system. Nueva York-San Francisco: Academic Press.

HysloP, J., 1990. Inka settlement planning. Austin: University of Texas Press.

JuleN, C., 2012. The Chinchaysuyu road and the definition of an Inca imperial landscape. En Highways, byways, and road systems in the pre-modern world, S. Alcock, J. Bodel \& R. Talbert, Eds., pp. 147-167. Nueva Jersey: Wiley-Blackwell.

MAtos, R., 1992. El Camino Real Inca y la carretera moderna en Chinchaycocha, Junín. En Estudios de arqueologia peruana, D. Bonavia, Ed., pp. 375-187. Lima: Fomciencias.

Morris, C. \& A. von HaGen, 1993. The Inka Empire and its andean origins. Nueva York: American Museum of Natural History.

MURRA, J., 1975. Formaciones económicas y políticas del mundo andino. Lima: Instituto de Estudios Peruanos.

MurRa, J., 1992. La visita de los valles de Sonqo en los yunka de coca de La Paz (1658-1670). Madrid: Sociedad Estatal Quinto Centenario.

MURRA, J., 2002. El mundo andino: población, medioambiente y economía. Lima: Pontificia Universidad Católica del Perú-Instituto de Estudios Peruanos.

NúÑez, L. \& A. NielseN (Eds.), 2011. Ruta, arqueología, historia y etnografía del tráfico sur andino. Córdoba: Encuentro.

Pease, F., 2004. Los últimos Incas del Cuzco. Lima: Instituto Nacional de Cultura.

RAMIREZ, S., 2005. To feed and be fed: the cosmological bases of authority and identity in the Andes. Stanford: Stanford University Press.

Rostworowski, M., 2009. Historia del Tahuantinsuyu. Lima: Instituto de Estudios Peruanos.

Urton, G., 2004. Historia de un mito. Pacariqtambo y el origen de los Inkas. Cusco: Centro Bartolomé de las Casas.

VITRY, C., 2000. Aportes para el estudio de caminos inkaicos: tramo Morohuasi-Inkahuasi, SaltaArgentina. Salta: Gofica.

Wright, K.; A. VAlencia, R. Wright \& G. McEWAn, 2000. Machu Picchu. A civil engineering marvel. Virginia: American Society of Civil Engineers Press.

ZuIDEMA, T., 2010. El calendario inca. Tiempo y espacio en la organización ritual del Cuzco. La idea del pasado. Lima: Fondo Editorial del Congreso del Perú-Fondo Editorial de la Pontificia Universidad Católica del Perú. 